\title{
Potentials and challenges towards application of perovskite solar cells
}

\author{
Jing Wei ${ }^{1,2}$, Chenglong Shi ${ }^{1,2}$, Yicheng Zhao ${ }^{1,2}$, Wenke Zhou ${ }^{1,2}$, Heng $\mathrm{Li}^{1,2}$, Rui Fu${ }^{1,2}$, Dapeng $\mathrm{Yu}^{1,2}$ \\ and Qing Zhao ${ }^{1,2^{*}}$
}

\begin{abstract}
The key progress in the development of solar cells based on mixed organic-inorganic halide perovskite was reviewed. Perovskite solar cells (PSCs) have developed rapidly and achieved highest efficiency exceeding $20 \%$ in these years. The origin, working principle and fabrication technology of PSCs are stated, and several promising methods to realize the industrialization of the solar cell modules have been put forward. Meanwhile, two main problems existing in PSCs have been pointed out, hysteresis in the photocurrent density-voltage measurement and the instability of perovskite, which have impacted the application of PSCs seriously. Efforts and study in order to solve these problems are also listed. The fundamental mechanism still needs further investigation so as to improve the performance of PSCs and realize their large-scale application eventually.
\end{abstract}

Keywords: perovskite solar cells, fabrication, industrialization, hysteresis, stability

\section{INTRODUCTION}

Over the past five years, we have witnessed the unprecedentedly rapid emergence of a new class of solar cell based on mixed organic-inorganic halide perovskite [1]. Organic-inorganic hybrid perovskite solar cells (PSCs) were first reported by Kojima et al. [2,3] as sensitized solar cells. In 2011, Im et al. [4] optimized the manufacture progress and improved the efficiency to $6.5 \%$, whereas the liquid electrolyte threatens the stability of perovskite film. Kim et al. [5] first applied solid electrolyte, spiro-OMeTAD, to PSCs, and greatly improved the chemical stability of the device. The highest efficiency of this solid device was improved to $9.7 \%$. Afterwards, PSCs opened up new design possibilities for high efficiency photoelectric devices and was ranked to top ten technological progress of the world in 2013 [6-11]. From then on, PSCs attracted considerable attention as the third generation solar cells and the efficiency skyrocketed to $20 \%$ in only two years [12-17].

"Perovskite" refers to the same crystal structure as calcium titanium oxide $\left(\mathrm{CaTiO}_{3}\right)$, which belongs to a face-centered cubic crystal system, as shown in Fig. $1 . \mathrm{CH}_{3} \mathrm{NH}_{3} \mathrm{PbI}_{3}$ is a kind of representative and widely used perovskite material in PSCs. In $\mathrm{CH}_{3} \mathrm{NH}_{3} \mathrm{PbI}_{3}, \mathrm{I}^{-}$ions and methylamine ions

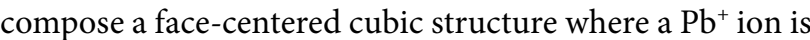
located in the center. This kind of structure owns many advantages. First, the 3D structure is composed by multihalogen octahedrons which are connected with each other by sharing corners. This kind of structure is more stable than both the face-shared and edge-shared crystal structures according to Pauling rule. Second, the gap in the corner-shared structure is bigger than that in the face-shared structure, which permits large ions to fill in. It can keep stable even with large amount of defects and is conducive to the diffusion of defects.

Particularly, methylamine lead halide has great advantages in photovoltaic conversion. Its absorbance is 10 times higher than that of traditional dye-sensitized solar cells (DSSCs). Furthermore, its absorption wavelength can be

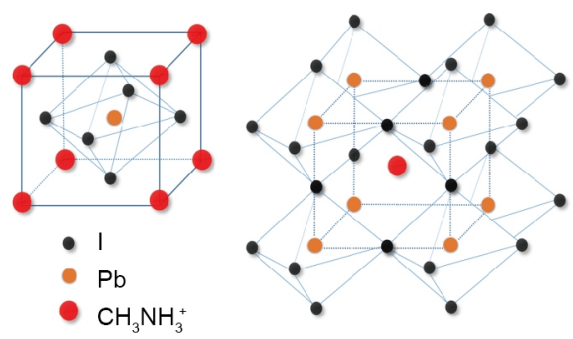

Figure 1 Structure diagram of perovskites.

\footnotetext{
${ }^{1}$ State Key Laboratory for Mesoscopic Physics, School of Physics, Peking University, Beijing 100871, China

${ }^{2}$ Collaborative Innovation Center of Quantum Matter, Beijing 100084, China

* Corresponding author (email: zhaoqing@pku.edu.cn)
} 
modified via substitution doping using different halide ions [18]. These characters make methylamine lead halide an ideal material for cost-effective solar cells. In this paper, we review the key progresses in the development of PSCs, including working principles, structure evolution and fabrication methods. Two main issues in the field of PSCs have also been pointed out: hysteresis in the Photocurrent density-voltage $(J-V)$ curves and instability in air and moisture, especially under light illumination. Several promising methods to realize the industrialization of the solar cell modules have been listed and their corresponding problems and potentials have been summarized.

\section{WORKING PRINCIPLE AND STRUCTURE DEVELOPMENT}

The working principle of the first PSCs is similar to traditional DSSCs. In the mesoporous structured device (Fig. 2a), the metal oxide mesoporous layer supports the perovskite crystal as a scaffold $[8,19]$. Moreover, the $\mathrm{TiO}_{2}$ layer is used as electron transport layer (ETL) that delivers electrons to the electrode. Meanwhile holes will be extracted by p-type materials, e.g., spiro-OMeTAD, and transported to the photocathode subsequently. Lee et al. [6] found the high electron mobility of perovskite, and first used insulating $\mathrm{Al}_{2} \mathrm{O}_{3}$ instead of $\mathrm{TiO}_{2}$ as the mesoporous layer, putting forward the concept of meso-superstructured solar cell (MSSC) (Fig. 2b). In this structure, electrons must be remained in the perovskite phase until they are collected at the planar $\mathrm{TiO}_{2}$-coated fluorine doped tin oxide (FTO) electrode. Therefore, $\mathrm{Al}_{2} \mathrm{O}_{3}$ does not act as an n-type oxide in DSSCs. This significant attempt demonstrates the high conductivity of perovskite and pushes forward the development of planar structure in PSCs.

After that, perovskite film with few defects was realized by vapor deposition [20]. The high quality film could transmit the photo-induced electrons into $\mathrm{TiO}_{2}$ blocking layer efficiently and was applied into a planar heterojunction device for the first time. As shown in Figs $3 a$ and $b$, the devices based on $\mathrm{FTO} /$ compact $\mathrm{TiO}_{2} /$ perovskite/spiro-OMeTAD/Au with the absence of mesoporous $\mathrm{TiO}_{2}$ layer have a similar operating mode with MSSCs. Afterwards, solution-based method was optimized to obtain high-quality perovskite layer. With simple process and low cost, planar structured PSCs were widely developed and became a promising candidate for the industrialization of PSCs. Meanwhile, PSCs with organic film structure were also developed and demonstrated high power conversion efficiency. Organic planar devices applied a ITO/ poly(3,4-ethylenedioxythiophene) (PEDOT):polystyrene sulfonate (PSS)/perovskite/[6,6]-phenyl- $\mathrm{C}_{61}$-butyric acid methyl ester (PCBM)/Ag structure, with the p-type conducting layer next to transparent electrode, constituting an $\mathrm{p}-\mathrm{i}-\mathrm{n}$ structure, as shown in Figs $3 \mathrm{c}$ and $\mathrm{d}[21,22]$.

\section{STUDY OF HYSTERESIS ISSUES}

Although the conversion efficiency has been rapidly increased in the development of PSCs, the fundamental mechanism of how perovskite works in the light or dark are still vague. Many abnormal phenomena have been found during the exploration of perovskite, especially the anomalous hysteresis in the $J-V$ curves [23-27].

Significant hysteresis can be observed in the $J-V$ curves under common scanning conditions. However, unlike what would be expected from typical capacitive charging and discharging effects, significant hysteresis still exists even at extremely slow scan rates. Snaith et al. [28] reported this phenomenon first, and claimed that each scanning voltage step had to be held for hundreds of seconds constantly in order to reach a stable current output.
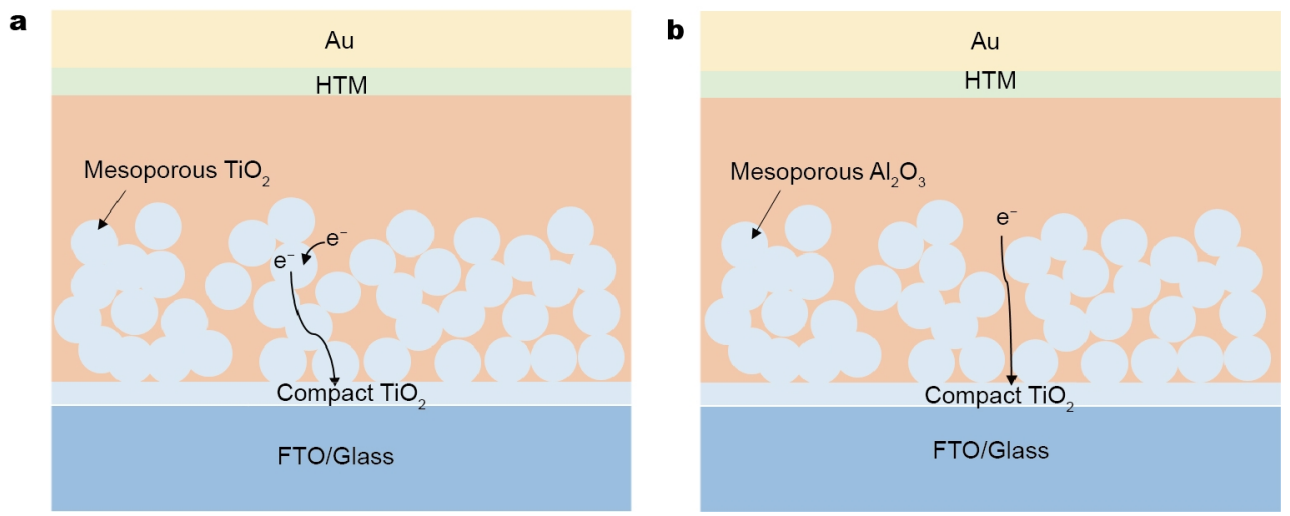

Figure 2 Schematic illustrating the charge transport in (a) perovskite-sensitized $\mathrm{TiO}_{2}$ solar cell and (b) non-injecting $\mathrm{Al}_{2} \mathrm{O}_{3}$-based solar cell. 

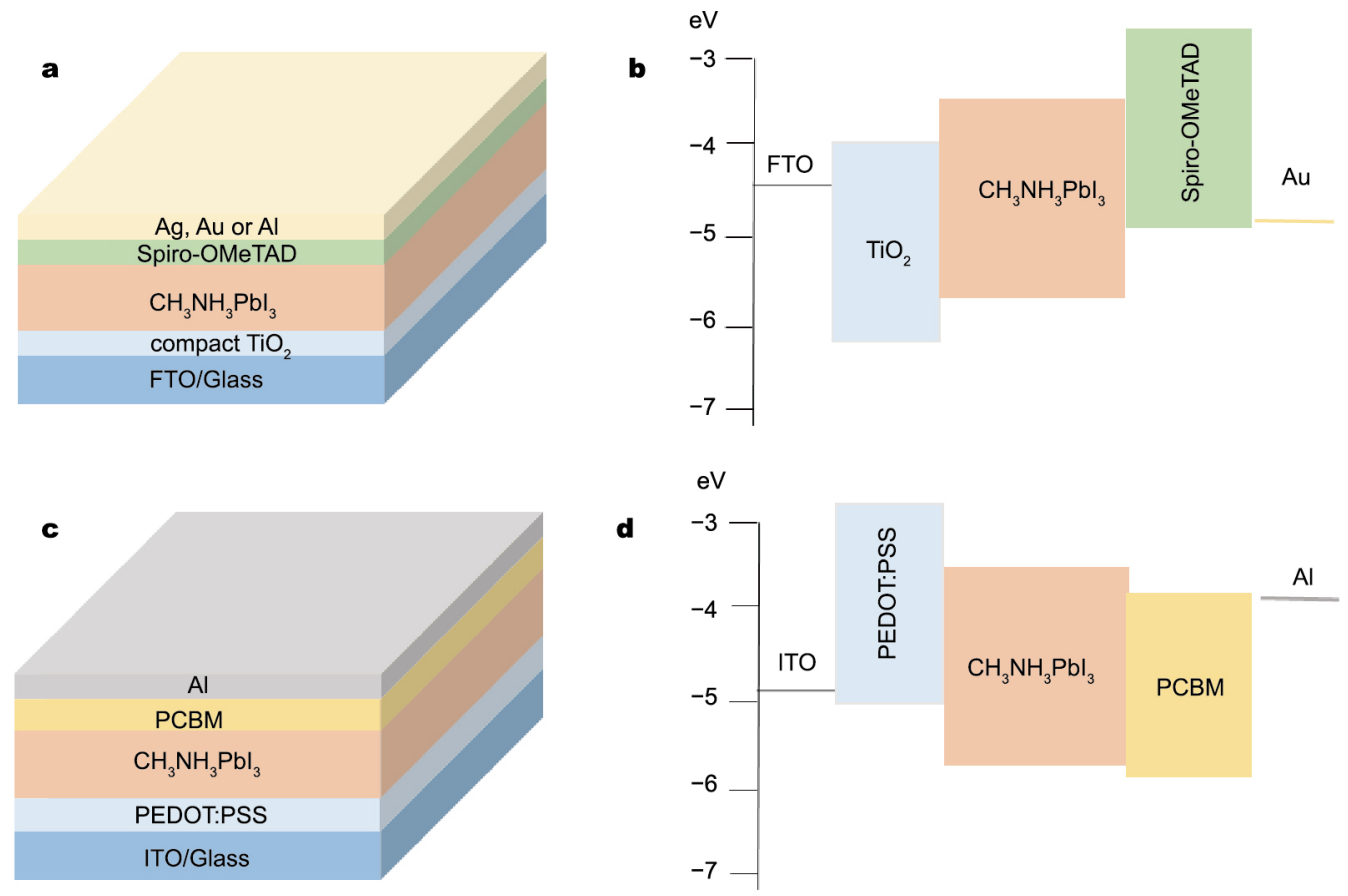

Figure 3 Structure and energy level diagram of perovskite solar cells based on planar heterojunction with inorganic ETL (a, b) and organic films (c, d).

As a result, the long-stepwise $J-V$ measurement for PSCs is necessary to evaluate the real performance of devices, as shown in Fig. 4.

To determine whether hysteresis originates from the perovskite layer, the $\mathrm{p}$ - or n-type collection materials (spiro-OMeTAD and $\mathrm{TiO}_{2}$ ), or the interface between the perovskite and the charge collection contacts, Snaith et al. [28] fabricated two kinds of MSSCs without compact $\mathrm{TiO}_{2}$ and spiro-OMeTAD, respectively. They found that the hysteresis was extremely severe in both of them. This result suggests that the hysteresis is not specifically caused by the compact $\mathrm{TiO}_{2}$ nor the hole transporter. The possible origination of hysteresis may be attributed to perovskite itself, or the interface between perovskite and charge collection layers. The increased hysteresis in both of these configurations (Au-only and FTO-only) indicates that it is influenced by the contact materials and it may root in an interface effect rather than a bulk property of perovskite [28].

Many groups paid their attentions to this phenomenon, and tried to uncover the possible mechanism [28-33]. Summarizing these researches, several possible origins and solutions were put forward to explain and control the hysteresis effect in PSCs.
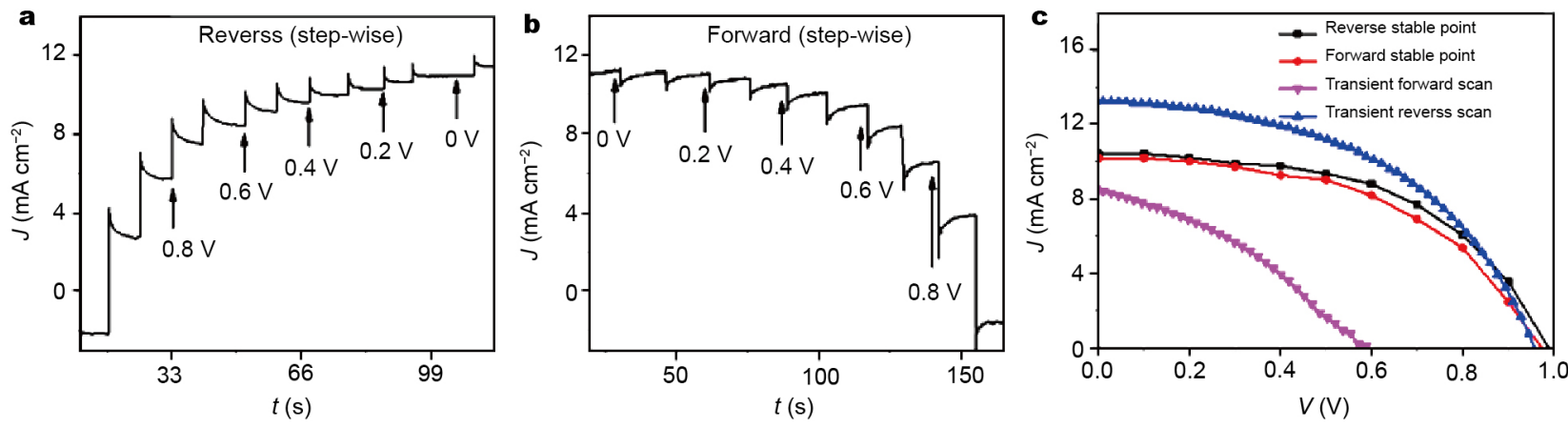

Figure 4 Long-stepwise $J$ - $V$ measurement of perovskite solar cells. (a,b) Reverse and forward stepwise scan measurement (with a dwell time of $\sim 10 \mathrm{~s}$ per $100 \mathrm{mV}$ step) for PSC. (c) $J$ - $V$ measurement of the stable-state scan (points extracted from the points where the arrows indicate in (a,b)) and transient scan in forward and reverse scans. Reprinted with permission for Ref. [29], Copyright 2014, the American Chemical Society. 


\section{Defects in perovskite film}

There are plenty of defects within or near the surface of the perovskite absorbers serving as traps for electrons and holes. By confining the photoluminescence light excitation region close to the surface of perovskite layer or through the perovskite films, Shao et al. [31] identified the location of these charge traps, and demonstrated the impact of trap states on the surface and grain boundaries of the perovskite material on photocurrent hysteresis. They also found that fullerene layers deposited on perovskite can passivate the charge trap states and then eliminate the notorious photocurrent hysteresis. This concept could well explain the much less hysteresis in the structure of PEDOT:PSS/perovskite/PCBM compared to $n-\mathrm{i}-\mathrm{p}$ structure based on $\mathrm{TiO}_{2}$ ETL [28-30].

\section{Ferroelectric effect}

The perovskite has been reported to possess ferroelectric properties, and some researchers attributed the hysteresis to ferroelectric effect $[34,35]$. When increasing the bias voltage, a slow polarization of the material may occur, which helps or hinders the carriers' transition and leads to hysteresis under different bias voltages. Wei et al. [29] found that mesoporous structure can reduce hysteresis, and with a thicker mesoporous $\mathrm{TiO}_{2}$ layer, hysteresis became weaker. From the measurement of electrical field-polarization loop, they speculated that the ferroelectric effect in $\mathrm{CH}_{3} \mathrm{NH}_{3} \mathrm{PbI}_{3}$ could result in hysteresis in the device. With a reasonable thickness of the mesoporous layer, they almost eliminated the hysteresis with a compromise of a slightly reduced power conversion efficiency.

\section{Photo-induced ion migration}

Unger et al. [30] found the strong dependence of the hysteresis on light and voltage biasing conditions in thin film devices for a period of time prior to the measurement, which made them to believe that photo-induced ion migration may additionally play an important role in the hysteresis of PSCs. Photo-excitation of perovskite could create halide vacancies that enable the migration of halide ions, enhancing the ionic conductivity of the material. Once these vacancies are created, an applied external bias can result in a redistribution of ions within the device, producing electric fields that aid or counteract charge carrier extraction, thus resulting in hysteresis of the $J-V$ curves [36]. Eames et al. [37] derived the activation energies for ionic migration in $\mathrm{CH}_{3} \mathrm{NH}_{3} \mathrm{PbI}_{3}$, compared it with kinetic data extracted from the $J-V$ response of a perovskite-based solar cell, and found vacancy-assisted migration of iodide ions with an activation energy of $0.6 \mathrm{eV}$. Azpiroz et al. [38] also pointed out that under working conditions, iodine-related defects were predicted to migrate at the electrodes on very short time scales $(<1 \mu \mathrm{s})$. Besides, they calculated the activation barriers of MA and $\mathrm{Pb}$ vacancies, and indicated that they were responsible for the slow response inherent to perovskites. Yang et al. [39] showed that methylammonium and formamidinium iodoplumbates were mixed conductors with a large fraction of ion conduction. They measured the stoichiometric polarization caused by the mixed conduction and demonstrated that the hysteresis can be explained by the build-up of stoichiometric gradients as a consequence of ion blocking interfaces.

\section{Capacitive effect}

Kim et al. [40] hold the viewpoint that as the hysteresis depends strongly on perovskite crystal size and mesoporous $\mathrm{TiO}_{2}$ layer, the origin of hysteresis may correlate to the capacitive characteristic of $\mathrm{CH}_{3} \mathrm{NH}_{3} \mathrm{PbI}_{3}$. The charging and discharging effect of the capacitance caused by bias causes the hysteresis.

\section{Solutions to suppress hysteresis}

Compared to n-i-p structure based on $\mathrm{TiO}_{2}$ ETL [28-30], the organic structure has unique advantage with much less hysteresis, which is attributed to the inhibiting effect of PCBM layer in ion migration on hysteresis [31,41]. However, the poor stability is a big challenge for the organic structure [42]. Chen et al. [43] combined the two types of structures by adding PCBM between perovskite and inorganic ETL as a modified layer for trap states in perovskite film and achieved the PSCs with suppressed hysteresis and high stability on large area. This work illustrates that PCBM plays an important role in solving the problem of hysteresis. Improving the quality of perovskite film can also get rid of hysteresis both in the organic and inorganic structures.

With similar viewpoint, Zhao et al. [44] added PCBM/polyethylene glycol (PEG) into the precursor of perovskite, to form organic network in the film. PCBM is homogeneously distributed throughout the film at perovskite grain boundaries [41]. And it has two functions here: 1) passivating trap states on grain boundaries; 2) providing conducting channels along grain boundaries for photo-generated electrons. These two functions effectively restrain the photocurrent hysteresis and improve the performance of the devices.

Seok and co-workers $[45,46]$ started the research of 
PSCs based on a new kind of material of perovskite family, formamidinium lead iodide $\left(\mathrm{FAPbI}_{3}\right)$. By the direct intramolecular exchange of dimethylsulfoxide (DMSO) molecules intercalated in $\mathrm{PbI}_{2}$ with formamidinium iodide, they obtained the high quality film of $\mathrm{FAPbI}_{3}$. And using films prepared by this technique, they fabricated PSCs based on planar structure with very little hysteresis and the maximum power conversion efficiency up to $20.1 \%$.

\section{STABILITY OF PSCs}

Stability always plays an important role in the entire development of PSCs. From the application of solid electrolyte to the adding of modifications, a variety of degradation mechanisms and solutions were put forward. Some remarkable improvements have been obtained and the operating life of PSCs has been extended to thousands of hours [47]. These improvements were achieved through the application of different materials, interfaces and device architecture optimizations, making the development of PSCs more promising. However, there is still a lack of clear understanding on the mechanism of perovskite and device degradation. Therefore, understanding the extrinsic and intrinsic degradation phenomena and mechanism is necessary to further improve the stability of PSCs.

\section{Oxygen and light induced degradation}

Zhou et al. [48] compared PSCs stored in dry air and nitrogen atmospheres respectively, finding degradation of perovskite in ambient air. Berhe et al. [49] analyzed the mechanism of device aging caused by oxygen and light. Fig. 5

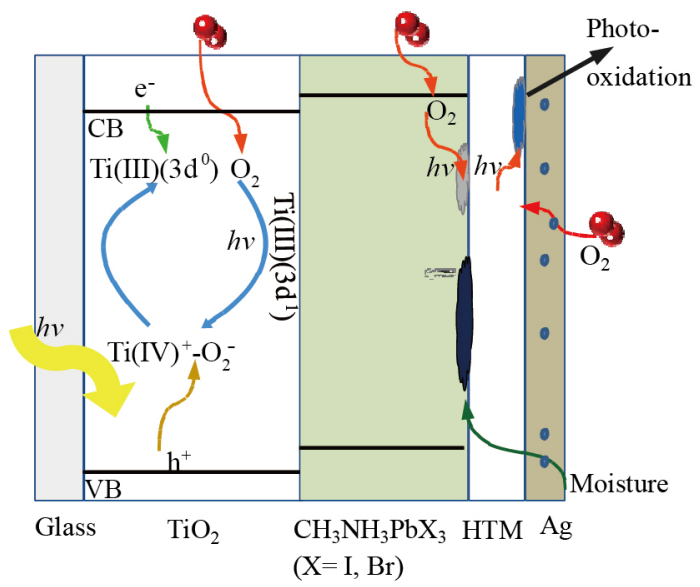

Figure 5 General schematic representation of hole-electron pair recombination, moisture dissolution of perovskite and photo oxidation processes at the interface between the HTM and counter electrode. Reprinted with permission from Ref. [49], Copyright 2016, the Royal Society of Chemistry. shows the schematic diagram representing the recombination process in PSCs with mesoporous $\mathrm{TiO}_{2}$. Oxygen would diffuse into the devices and the diffusion can be activated by UV illumination in the presence of $\mathrm{TiO}_{2}$ or organic molecules [50,51]. Then the produced oxygen free radicals will react with hole transporting materials or perovskite. $\mathrm{H}_{2} \mathrm{O}$ is also readily activated by oxygen and light in the presence of organic molecules.

\section{Moisture induced degradation}

As one of the main causes of perovskite degradation, moisture attracts most of the attentions for researchers [42,50,52-54]. Some suggested that moisture degrades the devices and the PSCs should be fabricated in the atmosphere as dry as possible [55]. While others holding the opposite opinion claimed that a proper humidity level ( $\sim 30 \%$ relative humidity) is essential for high quality perovskite film $[48,52]$. To study the effect of water molecules on the crystallized perovskite, Zhou et al. [56] sprayed various amounts of water vapor onto perovskite films and made these films into PSCs. Through measuring the capacitance, photoluminescence of the films, and performance of these PSCs, they found that water molecules can deactivate the defect states due to hydrogen bonding with uncoordinated ions on the surface of perovskite film (Fig. 6). This work emphasized the effectiveness of hydroxyl in $\mathrm{H}_{2} \mathrm{O}$ to heal the defects due to dangling bonds on the material surface, providing theoretical support for the moisture being beneficial to the improvement of the quality of perovskite to some extent.

Despite the effect on the crystallization, the fact is recognized indisputably that moisture and water will greatly accelerate the perovskite degradation, especially for the long-term stability. A number of endeavors have been directed to overcome this problem. One strategy is to develop new kind of stable perovskite materials, but the improper bandgap or exciton binding energy always results in a very low efficiency of devices [57,58]. Applying a water-resisting layer on the surface of perovskite film was demonstrated to be an effective way to enhance the moisture resistance of devices $[47,54,59]$. In addition, crystal crosslinking with modified molecule, or hydrophobic additives blending into perovskite also improves the stability, even the efficiency of PSCs [60]. Zhao et al. [44] added hydrophobic polymer (PEG) into the precursor of perovskite, achieving uniform perovskite films based on a novel polymer-scaffold architecture via a mild-temperature process (Fig. 7). The unsealed devices showed a strong humidity resistance which could retain high output 

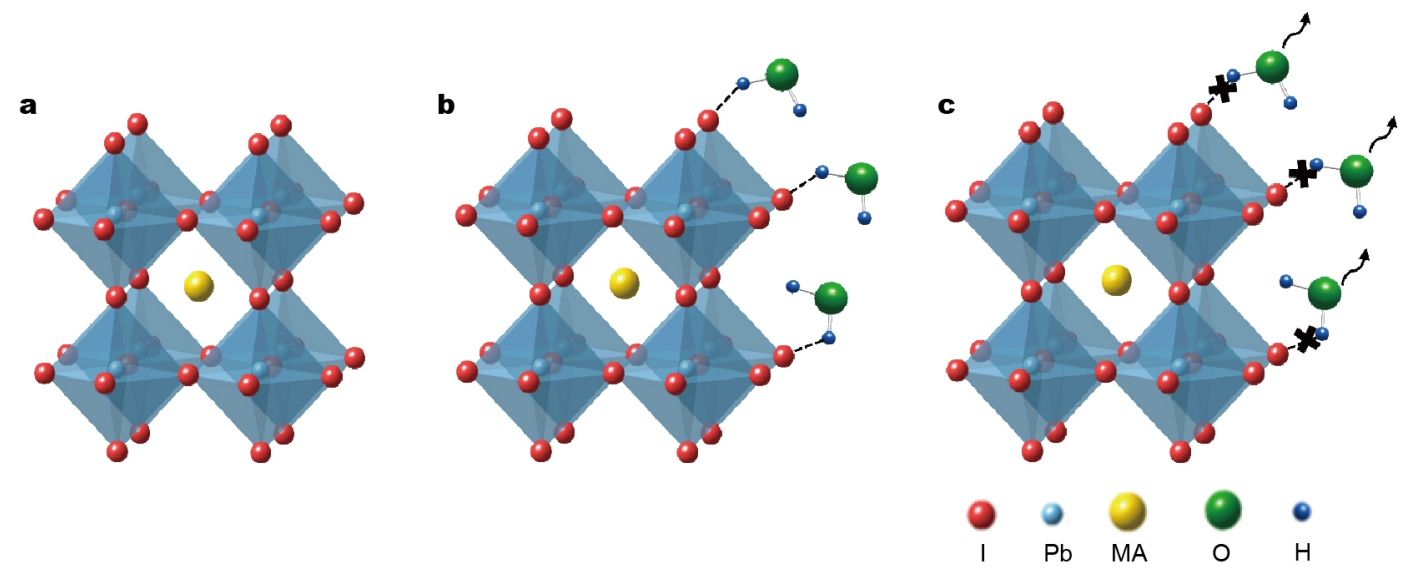

Figure 6 Schematic illustrations of (a) perovskite crystals before vapor spray, (b) interaction between water molecules and perovskite crystals after vapor spray, and (c) disappearance of the interaction after water molecules escape. Reprinted with permission for Ref. [56], Copyright 2014, the American Chemical Society.

a
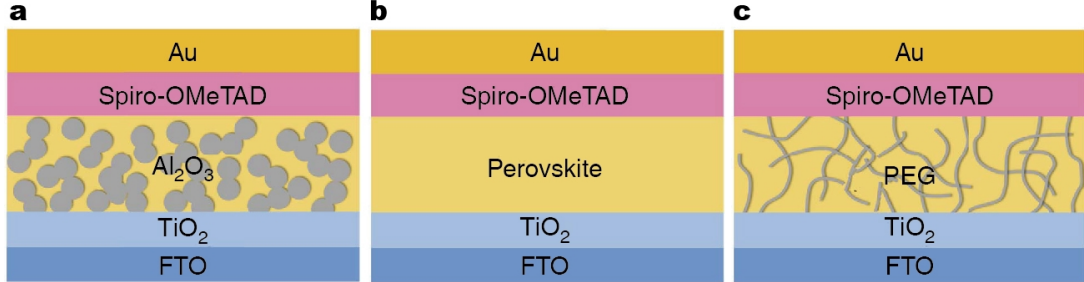

d

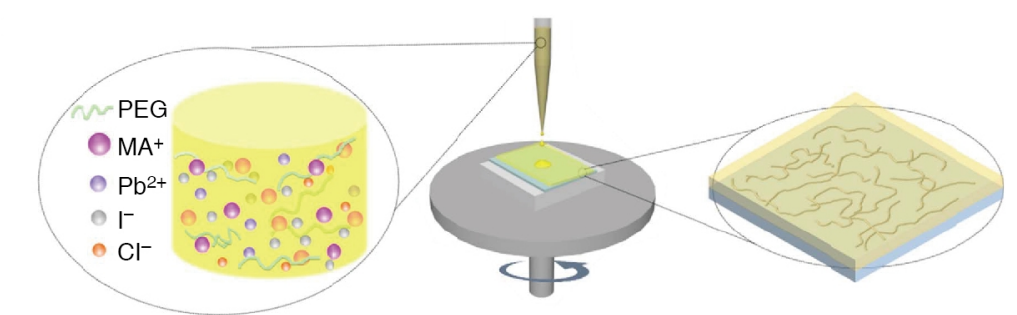

Figure 7 Scheme of polymer-scaffold perovskite solar cells. Schematic diagram of mesoporous-scaffold-structured PSC (a), planar-heterojunctionstructured PSC (b) and polymer-scaffold structured PSC (c). (d) Schematic diagram showing the fabrication process of perovskite film with polymer scaffold using one-step spin coating method. Reprinted with permission from Ref. [44], Copyright 2016, Nature Publishing Group.

for up to $300 \mathrm{~h}$ in the environment of $70 \%$ relative humidity. More strikingly, these polymer-scaffold solar cells demonstrated a unique self-healing behavior: perovskite film and solar cell devices could recover rapidly after removed from the water vapor. The underlying reason for the amazing self-healing behavior has been attributed to hydrogen bonding between methylamine ions and PEG molecule. This work provides a simple method to get PSCs with high stability and performance, demonstrating the value of cheap polymer in PSCs towards commercialization.

Beyond the factors discussed above, temperature and electric field can also induce the degradation of perovskite [61]. In addition to identifying the main causes of degradation, it is critical to isolate the key origin of it. There are various issues associated with the degradation of perovskite, and a comprehensive understanding of them is required to achieve practical outdoor application of the PSCs.

\section{DEVELOPMENT OF COMMERCIAL-SCALE PRODUCT}

The rapid increased efficiency of thin film solar cells using perovskite has made it a highly promising technology for solar energy conversion $[33,39,62]$. The highest conversion efficiency has exceeded $20 \%$ in labs [45]. Currently, solar cells for large-scale application has become an important research direction [63]. Although many novel processes have been investigated towards the goals of achieving 
cost-effective solar cells, spin coating is still the mainstream [64-66]. However, spin coating process cannot be used for large-area devices. Based on previous exploration of organic photovoltaic industrialization, some researchers put forward several promising methods to realize PSCs with large area.

\section{Vapor deposition}

Compatible with industry equipment, vapor deposition is one of the simplest techniques. Nevertheless its high pollution and high vacuum requirement add the fabricating cost. In actual production, low-temperature, operation in air and environmentally friendly method is of great significance to research and application. As a result, vapor deposition may be not the best choice for industrialization of PSCs.

\section{Spray deposition}

Spray deposition is widely used for solar cells in commercial production and is one of the cheapest processes for polymer solution coating. Combining the roll-to-roll process with spray deposition of perovskite could be an ideal solution for low-cost power generation [66]. As early as 2007, spray painting method was explored for a cost-efficient technique for the fabrication of large area organic photovoltaic (OPVs) as a scalable coating method, and was optimized by Vak et al. [67] to a vacuum-free process. The spray process is shown in Fig. 8a. Seven years later in 2014, Barrows et al. [68] used a similar method to deposit perovskite film. With the optimization of processing parameters, a power conversion efficiency of $11 \%$ was obtained.

In 2014, inkjet printing was used to convert spin-coated $\mathrm{PbI}_{2}$ layer to perovskite layer and print carbon electrodes [69]. The process is promising as it is scalable and vacuum free. It will be more ideal if all layers can be printed.
In 2015, Hwang et al. [70] put forward a roll-to-roll production of fully printed PSCs towards large scale (Fig. 8b). Roll-to-roll fabrication method has been widely used in the process of OPVs [71]. In this field, slot-die coating has been well studied. Slot-die coating produces a uniform stripe with well-defined edges, which is required in conventional module design, and is classified as pre-metered coating. In this work, Hwang et al. demonstrated the fabrication of fully slot-die coated PSCs. With the exception of evaporated metal electrode, all layers were fabricated via scalable process, slot-die coating.

To expand the fabrication process, Vak et al. [72] developed a 3D printer based slot-die coater. As shown in Fig. $8 \mathrm{c}$, a typical 3D printer can control the $x y z$ positions and coating speed. The temperature of the nozzle and the bed can also be controlled. Therefore, a fully PC-controlled system could be easily realized.

\section{Fully printed deposition}

Based on the industry development of OPVs and DSSCs, it will be not difficult to find a proper method for large-scale fabrication of PSCs. Spray deposition, slot-die coating and $3 \mathrm{D}$ printer all could be good choices. Beyond that, research for the life-cycle assessment of energy and environmental impacts is also an important aspect for the real application of PSCs [73].

\section{CONCLUSION AND PROSPECTS}

In this review, we give an overview of the historical progress in PSCs and retrospect its working principle and several basic device architectures. The high efficiency, cost-effective materials and simple process of PSCs make them economically viable for commercialization, but there still exist some problems to be solved. Hysteresis and stability of PSCs
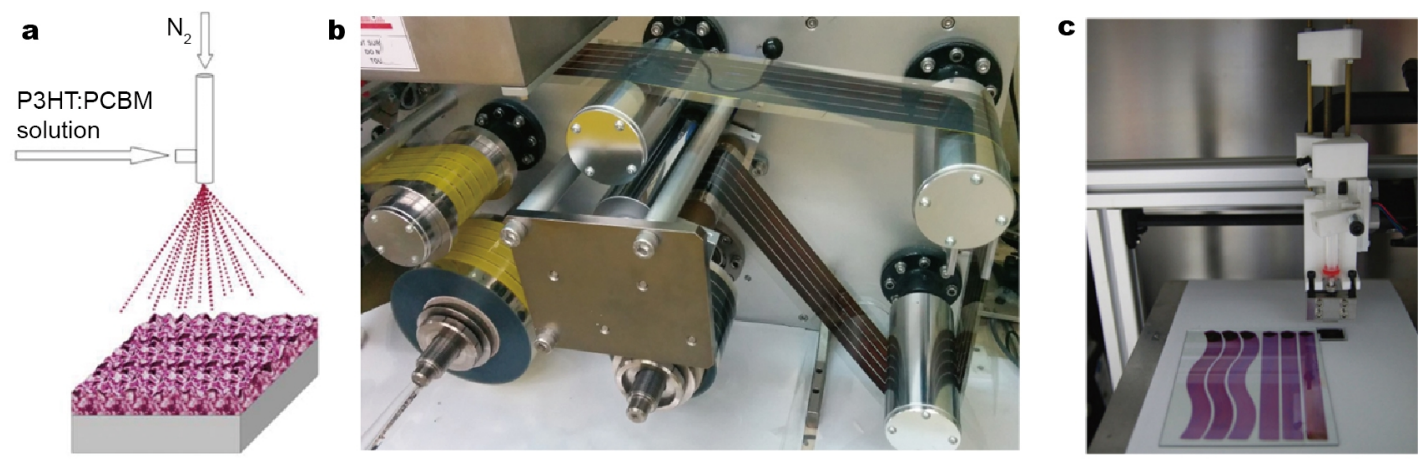

Figure 8 Deposition method for perovskite solar cells. (a) Schematic illustration of the spray process (reprinted with permission from Ref. [67], Copyright 2007, American Institute of Physics); (b) roll-to-roll production of perovskite solar cells (reprinted with permission from Ref. [70], Copyright 2015, WILEY-VCH); (c) 3D printer for solution processing (reprinted with permission from Ref. [72], Copyright 2015, WILEY-VCH). 
keep two main plaguing problems. Although some groups can restrain photocurrent hysteresis by fullerene passivation or new materials, the real mechanism are still unclear. More seriously, the stability of these cells is still not able to reach the requirement for industrialization. It is urgent to understand the degradation mechanism as well as exploit new solutions to realize a more-than-10-years operation lifetime standard as its Si counterparts. Furthermore, more attention should be paid to the life-cycle assessment of energy and environmental impacts studies of PSCs. Future research should be directed to improving the system performance and the device lifetime.

\section{Received 18 June 2016; accepted 28 July 2016;} published online 10 August 2016

1 Kagan CR. Organic-inorganic hybrid materials as semiconducting channels in thin-film field-effect transistors. Science, 1999, 286: 945-947

2 Agarwal V, Faelber K, Schmieder P, et al. High-resolution doublequantum deuterium magic angle spinning solid-state NMR spectroscopy of perdeuterated proteins. J Am Chem Soc, 2009, 131: $2-3$

3 Kojimaa A, Teshimad K, Shiraic Y, Tsutomu Miyasakaa. Novel Photoelectrochemical Cell with Mesoscopic Electrodes Sensitized by Lead-halide Compounds. 212th ECS Meeting, 2006, Abstract \#352

$4 \mathrm{Im} \mathrm{JH}$, Lee CR, Lee JW, et al. 6.5\% Efficient perovskite quantumdot-sensitized solar cell. Nanoscale, 2011, 3: 4088-4093

5 Kim HS, Lee CR, Im JH, et al. Lead iodide perovskite sensitized all-solid-state submicron thin film mesoscopic solar cell with efficiency exceeding 9\%. Sci Rep, 2012, 2: 591

6 Lee MM, Teuscher J, Miyasaka T, et al. Efficient hybrid solar cells based on meso-superstructured organometal halide perovskites. Science, 2012, 338: 643-647

7 Chen Q, Zhou H, Hong Z, et al. Planar heterojunction perovskite solar cells via vapor-assisted solution process. J Am Chem Soc, 2014, 136: 622-625

8 Burschka J, Pellet N, Moon SJ, et al. Sequential deposition as a route to high-performance perovskite-sensitized solar cells. Nature, 2013, 499: 316-319

9 Snaith HJ. Perovskites: the emergence of a new era for low-cost, high-efficiency solar cells. J Phys Chem Lett, 2013, 4: 3623-3630

$10 \mathrm{Heo} \mathrm{JH}, \mathrm{Im} \mathrm{SH}, \mathrm{Noh} \mathrm{JH}$, et al. Efficient inorganic-organic hybrid heterojunction solar cells containing perovskite compound and polymeric hole conductors. Nat Photon, 2013, 7: 486-491

11 Hodes G, Cahen D. Photovoltaics: perovskite cells roll forward. Nat Photon, 2014, 8: 87-88

12 Ball JM, Lee MM, Hey A, et al. Low-temperature processed mesosuperstructured to thin-film perovskite solar cells. Energy Environ Sci, 2013, 6: 1739-1743

13 Bi D, Yang L, Boschloo G, et al. Effect of different hole transport materials on recombination in $\mathrm{CH}_{3} \mathrm{NH}_{3} \mathrm{PbI}_{3}$ perovskite-sensitized mesoscopic solar cells. J Phys Chem Lett, 2013, 4: 1532-1536

14 Conings B, Baeten L, De Dobbelaere C, et al. Perovskite-based hybrid solar cells exceeding $10 \%$ efficiency with high reproducibility using a thin film sandwich approach. Adv Mater, 2014, 26: 2041-2046
15 Liu D, Kelly TL. Perovskite solar cells with a planar heterojunction structure prepared using room-temperature solution processing techniques. Nat Photon, 2013, 8: 133-138

16 Kim HS, Lee JW, Yantara N, et al. High efficiency solid-state sensitized solar cell-based on submicrometer rutile $\mathrm{TiO}_{2}$ nanorod and $\mathrm{CH}_{3} \mathrm{NH}_{3} \mathrm{PbI}_{3}$ perovskite sensitizer. Nano Lett, 2013, 13: 2412-2417

17 Chen Q, Zhou H, Fang Y, et al. The optoelectronic role of chlorine in $\mathrm{CH}_{3} \mathrm{NH}_{3} \mathrm{PbI}_{3}(\mathrm{Cl})$-based perovskite solar cells. Nat Commun, 2015, 6: 7269

18 Wei J, Zhao Q, Li H, et al. Perovskite solar cells: promise of photovoltaics. Sci Sin Tech, 2014, 44: 801-821

19 Etgar $\mathrm{L}, \mathrm{Gao} \mathrm{P}$, Xue Z, et al. Mesoscopic $\mathrm{CH}_{3} \mathrm{NH}_{3} \mathrm{PbI}_{3} / \mathrm{TiO}_{2}$ heterojunction solar cells. J Am Chem Soc, 2012, 134: 17396-17399

20 Liu M, Johnston MB, Snaith HJ. Efficient planar heterojunction perovskite solar cells by vapour deposition. Nature, 2013, 501: 395-398

21 Seo J, Park S, Chan Kim Y, et al. Benefits of very thin PCBM and LiF layers for solution-processed p-i-n perovskite solar cells. Energy Environ Sci, 2014, 7: 2642

22 Jeng JY, Chiang YF, Lee $\mathrm{MH}$, et al. $\mathrm{CH}_{3} \mathrm{NH}_{3} \mathrm{PbI}_{3}$ Perovskite/fullerene planar-heterojunction hybrid solar cells. Adv Mater, 2013, 25: 3727-3732

23 Xing G, Wu B, Chen $\mathrm{S}$, et al. Interfacial electron transfer barrier at compact $\mathrm{TiO}_{2} / \mathrm{CH}_{3} \mathrm{NH}_{3} \mathrm{PbI}_{3}$ heterojunction. Small, 2015, 11: 3606-3613

24 Qin P, Paulose M, Dar MI, et al. Stable and efficient perovskite solar cells based on titania nanotube arrays. Small, 2015, 11: 5533-5539

25 Nie W, Tsai H, Asadpour R, et al. High-efficiency solution-processed perovskite solar cells with millimeter-scale grains. Science, 2015, 347: 522-525

26 Xiao Z, Yuan Y, Shao Y, et al. Giant switchable photovoltaic effect in organometal trihalide perovskite devices. Nat Mater, 2015, 14: 193-198

27 Grätzel M. The light and shade of perovskite solar cells. Nat Mater, 2014, 13: 838-842

28 Snaith HJ, Abate A, Ball JM, et al. Anomalous hysteresis in perovskite solar cells. J Phys Chem Lett, 2014, 5: 1511-1515

29 Wei J, Zhao Y, Li H, et al. Hysteresis analysis based on the ferroelectric effect in hybrid perovskite solar cells. J Phys Chem Lett, 2014, 5: $3937-3945$

30 Unger EL, Hoke ET, Bailie CD, et al. Hysteresis and transient behavior in current-voltage measurements of hybrid-perovskite absorber solar cells. Energy Environ Sci, 2014, 7: 3690-3698

31 Shao Y, Xiao Z, Bi C, et al. Origin and elimination of photocurrent hysteresis by fullerene passivation in $\mathrm{CH}_{3} \mathrm{NH}_{3} \mathrm{PbI}_{3}$ planar heterojunction solar cells. Nat Commun, 2014, 5: 5784

32 Motta C, El-Mellouhi F, Kais S, et al. Revealing the role of organic cations in hybrid halide perovskite $\mathrm{CH}_{3} \mathrm{NH}_{3} \mathrm{PbI}_{3}$. Nat Commun, 2015, 6: 7026

33 Tress W, Marinova N, Moehl T, et al. Understanding the rate-dependent $J-V$ hysteresis, slow time component, and aging in $\mathrm{CH}_{3} \mathrm{NH}_{3} \mathrm{PbI}_{3}$ perovskite solar cells: the role of a compensated electric field. Energy Environ Sci, 2015, 8: 995-1004

34 Chen HW, Sakai N, Ikegami M, et al. Emergence of hysteresis and transient ferroelectric response in organo-lead halide perovskite solar cells. J Phys Chem Lett, 2015, 6: 164-169

35 Frost JM, Butler KT, Walsh A. Molecular ferroelectric contributions to anomalous hysteresis in hybrid perovskite solar cells. APL Mater, 2014, 2: 081506

36 Zhang Y, Liu M, Eperon GE, et al. Charge selective contacts, mobile ions and anomalous hysteresis in organic-inorganic perovskite solar cells. Mater Horiz, 2015, 2: 315-322 
37 Eames C, Frost JM, Barnes PRF, et al. Ionic transport in hybrid lead iodide perovskite solar cells. Nat Commun, 2015, 6: 7497

38 Azpiroz JM, Mosconi E, Bisquert J, et al. Defect migration in methylammonium lead iodide and its role in perovskite solar cell operation. Energy Environ Sci, 2015, 8: 2118-2127

39 Yang TY, Gregori G, Pellet N, et al. The significance of ion conduction in a hybrid organic-inorganic lead-iodide-based perovskite photosensitizer. Angew Chem Int Ed, 2015, 54: 7905-7910

40 Kim HS, Park NG. Parameters affecting $I-V$ hysteresis of $\mathrm{CH}_{3} \mathrm{NH}_{3} \mathrm{PbI}_{3}$ perovskite solar cells: effects of perovskite crystal size and mesoporous $\mathrm{TiO}_{2}$ layer. J Phys Chem Lett, 2014, 5: 2927-2934

41 Yang WS, Noh JH, Jeon NJ, et al. High-performance photovoltaic perovskite layers fabricated through intramolecular exchange. Science, 2015, 348: 1234-1237

42 Jeon NJ, Noh JH, Yang WS, et al. Compositional engineering of perovskite materials for high-performance solar cells. Nature, 2015, 517: 476-480

$43 \mathrm{Xu}$ J, Buin $\mathrm{A}$, Ip $\mathrm{AH}$, et al. Perovskite-fullerene hybrid materials suppress hysteresis in planar diodes. Nat Commun, 2015, 6: 7081

44 Zhao Y, Wei J, Li H, et al. A polymer scaffold for self-healing perovskite solar cells. Nat Commun, 2016, 7: 10228

45 Chen W, Wu Y, Yue Y, et al. Efficient and stable large-area perovskite solar cells with inorganic charge extraction layers. Science, 2015, 350: 944-948

46 Wei J, Li H, Zhao Y, et al. Suppressed hysteresis and improved stability in perovskite solar cells with conductive organic network. Nano Energy, 2016, 26: 139-147

47 Mei A, Li X, Liu L, et al. A hole-conductor-free, fully printable mesoscopic perovskite solar cell with high stability. Science, 2014, 345: 295-298

48 Zhou H, Chen Q, Li G, et al. Interface engineering of highly efficient perovskite solar cells. Science, 2014, 345: 542-546

49 Berhe TA, Su WN, Chen $\mathrm{CH}$, et al. Organometal halide perovskite solar cells: degradation and stability. Energy Environ Sci, 2016, 9: 323-356

50 Xiong J, Yang B, Cao C, et al. Interface degradation of perovskite solar cells and its modification using an annealing-free $\mathrm{TiO}_{2} \mathrm{NPs}$ layer. Organic Electrons, 2016, 30: 30-35

51 Reese MO, Nardes AM, Rupert BL, et al. Photoinduced degradation of polymer and polymer-fullerene active layers: experiment and theory. Adv Funct Mater, 2010, 20: 3476-3483

52 You J, Yang YM, Hong Z, et al. Moisture assisted perovskite film growth for high performance solar cells. Appl Phys Lett, 2014, 105: 183902

53 Eperon GE, Habisreutinger SN, Leijtens T, et al. The importance of moisture in hybrid lead halide perovskite thin film fabrication. ACS Nano, 2015, 9: 9380-9393

54 You J, Meng L, Song TB, et al. Improved air stability of perovskite solar cells via solution-processed metal oxide transport layers. Nat Nanotech, 2016, 11: 75-81

55 Noh JH, Im SH, Heo JH, et al. Chemical management for colorful, efficient, and stable inorganic-organic hybrid nanostructured solar cells. Nano Lett, 2013, 13: 1764-1769

56 Zhou W, Zhao Y, Shi C, et al. Reversible healing effect of water molecules on fully crystallized metal-halide perovskite film. J Phys Chem C, 2016, 120: 4759-4765

57 Smith IC, Hoke ET, Solis-Ibarra D, et al. A layered hybrid perovskite solar-cell absorber with enhanced moisture stability. Angew Chem Int Ed, 2014, 53: 11232-11235

58 Lyu M, Yun JH, Cai M, et al. Organic-inorganic bismuth
(III)-based material: a lead-free, air-stable and solution-processable light-absorber beyond organolead perovskites. Nano Res, 2016, 9: 692-702

59 Habisreutinger SN, Leijtens T, Eperon GE, et al. Carbon nanotube/polymer composites as a highly stable hole collection layer in perovskite solar cells. Nano Lett, 2014, 14: 5561-5568

$60 \mathrm{Li}$ X, Ibrahim Dar M, Yi C, et al. Improved performance and stability of perovskite solar cells by crystal crosslinking with alkylphosphonic acid $\omega$-ammonium chlorides. Nat Chem, 2015, 7: 703-711

61 Zhao Y, Zhu K. Organic-inorganic hybrid lead halide perovskites for optoelectronic and electronic applications. Chem Soc Rev, 2016, 45: 655-689

62 Lee YH, Luo J, Humphry-Baker R, et al. Unraveling the reasons for efficiency loss in perovskite solar cells. Adv Funct Mater, 2015, 25: 3925-3933

63 Espinosa N, Hösel M, Jørgensen M, et al. Large scale deployment of polymer solar cells on land, on sea and in the air. Energy Environ Sci, 2014, 7: 855-866

64 Vak D, van Embden J, Wong WWH, et al. Optically monitored spray coating system for the controlled deposition of the photoactive layer in organic solar cells. Appl Phys Lett, 2015, 106: 033302

65 Zhang T, Yang M, Zhao Y, et al. Controllable sequential deposition of planar $\mathrm{CH}_{3} \mathrm{NH}_{3} \mathrm{PbI}_{3}$ perovskite films via adjustable volume expansion. Nano Lett, 2015, 15: 3959-3963

66 Jung YS, Hwang K, Scholes FH, et al. Differentially pumped spray deposition as a rapid screening tool for organic and perovskite solar cells. Sci Rep, 2016, 6: 20357

67 Vak D, Kim SS, Jo J, et al. Fabrication of organic bulk heterojunction solar cells by a spray deposition method for low-cost power generation. Appl Phys Lett, 2007, 91: 081102

68 Barrows AT, Pearson AJ, Kwak CK, et al. Efficient planar heterojunction mixed-halide perovskite solar cells deposited via spraydeposition. Energy Environ Sci, 2014, 7: 2944-2950

69 Wei Z, Chen $\mathrm{H}$, Yan $\mathrm{K}$, et al. Inkjet printing and instant chemical transformation of a $\mathrm{CH}_{3} \mathrm{NH}_{3} \mathrm{PbI}_{3} /$ nanocarbon electrode and interface for planar perovskite solar cells. Angew Chem Int Ed, 2014, 53: $13239-13243$

70 Hwang K, Jung YS, Heo YJ, et al. Toward large scale roll-to-roll production of fully printed perovskite solar cells. Adv Mater, 2015, 27: $1241-1247$

71 Søndergaard R, Hösel M, Angmo D, et al. Roll-to-roll fabrication of polymer solar cells. Mater Today, 2012, 15: 36-49

72 Vak D, Hwang K, Faulks A, et al. Solar cells: 3D printer based slotdie coater as a lab-to-fab translation tool for solution-processed solar cells. Adv Energy Mater, 2015, 5: 1401539

73 Gong J, Darling SB, You F. Perovskite photovoltaics: life-cycle assessment of energy and environmental impacts. Energy Environ Sci, 2015, 8: 1953-1968

Acknowledgments This work was supported by the National Basic Research Program of China (2013CB932602) from Ministry of Science and Technology, China, and the National Natural Science Foundation of China (NSFC51272007, 61571015, and 91433102).

Author contributions Wei J, Shi $\mathrm{C}$ and Zhao Q prepared the manuscript with support from Zhao Y, Zhou W, Li H, Fu R and Yu D. All authors contributed to general discussion.

Conflict of interest The authors declare that they have no conflict of interest. 

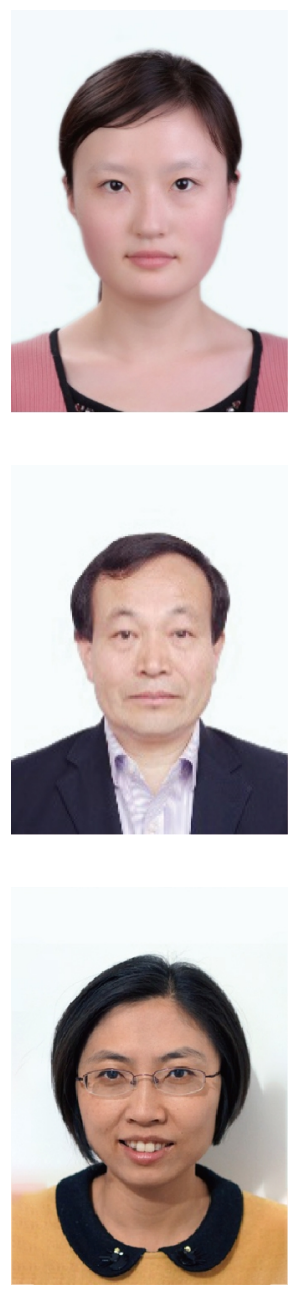

Jing Wei is a PhD candidate of the School of Physics at Peking University under the supervision of Prof. Dapeng Yu and Prof. Qing Zhao. She received her BSc degree (2012) from the School of Microelectronics and Solid-State Electronics, University of Electronic Science and Technology of China. She joined Prof. Yu's group in summer 2012, and she is especially interested in new types of photovoltaic materials and devices.

Dapeng Yu is a Chang Kung Professorship in physics in the School of Physics, Peking University. He received his PhD degree (1993) in the Laboratoire de Physicque des Solides, Université Paris-sud, Orsay, France, and then joined the Department of Physics, Peking University in 1995. His current interests are 1D semiconductor nanowires, transport in low-D materials, and single DNA detection/sequencing via solid state nanopore microscope.

Qing Zhao is an associate professor in the School of Physics, Peking University. She received her PhD degree (2006) from the School of Physics, Peking University. She spent two years working as a post-doctoral fellow in the Department of Bioengineering, University of Washington, USA. Her current research interests include novel flexible photovoltaic and energy storage devices based on nanostructures, and single molecule detection based on solid-state nanopores.

\section{钙钛矿太阳能电池工业化面临的潜力和挑战}

魏静 ${ }^{1,2}$, 施成龙 ${ }^{1,2}$, 赵怡程 ${ }^{1,2}$, 周文可 ${ }^{1,2}$, 李恒 ${ }^{1,2}$, 伏睿 ${ }^{1,2}$, 俞大鹏 ${ }^{1,2}$, 赵清 $1,2^{*}$

摘要 本文对有机-无机杂化钙钛矿太阳能电池的主要发展进程进行了阐述和研究. 钙钛矿电池因其高效率、低成本引起了业界广泛关注, 并在短短几年内迅速发展, 最高效率已经超过 $20 \%$. 本文通过讨论钲钛矿电池的起源、发展、工作原理和结构的变迁, 提出了几种最有可 能实现工业化目标的器件制备方案, 并分别对其进行了分析. 同时, 文章指出了目前影响钻钛矿电池产业化发展和应用的两个主要问题: 回 滞现象和稳定性, 对其产生的原因进行了分析, 并总结了几种可能的解决办法. 